УДК 616.12-073.7

\title{
АНАЛИЗ НИЗКОАМПЛИТУДНЫХ СИГНАЛОВ ЭЛЕКТРИЧЕСКОЙ АКТИВНОСТИ СЕРДЦА
}

ИВАНУШКИНА Н. Г., ИВАНЬКО Е. О., ТИМОФЕЕВ В. И.

\author{
Национальный технический университет Украины \\ «Киевский политехнический институт», \\ Украина, Киев, 03056, пр-т Победы 37
}

\begin{abstract}
Аннотация. Рассмотрен неинвазивный подход к оцениванию состояния сердечно-сосудистой системы на основе обнаружения тонких проявлений электрической активности сердца с помощью технологий высокого разрешения в электрокардиографии. Разработаны комбинированные методы анализа низкоамплитудных компонент электрокардиосигналов: для выявления поздних потенциалов, представляющих патологическую электрическую активность сердца, а также для разделения электрокардиосигналов плода и матери, полученных при абдоминальной записи. Комбинирование методов основано на создании собственных подпространств сигналов и шума при различных сочетаниях разложения в базисе собственных векторов, анализа главных компонент, анализа независимых компонент и вейвлет-анализа. Проведенные численные эксперименты показали, что предложенные методы позволяют устранить шумы и помехи в зарегистрированных электрокардиограммах, а также выявить изменения морфологии зубцов и комплексов в кардиоциклах, что дает возможность выполнить раннюю диагностику в случае патологии
\end{abstract}

Ключевые слова: электрическая активность сердца; поздние потенциалы предсердий и желудочков; абдоминальные электрокардиосигналы; кардиоциклы плода и матери; вейвлет-анализ; метод слепого разделения источников; анализ главных компонент; анализ независимых компонент; разложение в базисе собственных векторов

\section{ВВЕДЕНИЕ}

Известно, что жизнедеятельность любого организма сопровождается протеканием внутри него электрических биотоков, которые возникают как следствие электрической активности клеток. Электрическая активность сердца (ЭАС) характеризуется совокупностью электрических явлений, которые возможно регистрировать с помощью различных методов электрокардиографии (ЭКГ), дающей картину изменений во времени разности потенциалов на поверхности тела человека [1-3]. Регистрируемый сигнал от поверхностных электродов ЭКГ, отражая функцию или дисфункцию ионных каналов, представляет собой интеграцию электрофизиологических процессов миллионов кардиомиоцитов.

Несмотря на то, что методу электрокардиографии более 100 лет, происходит непрерывное совершенствование электрокардиографических технологий. Развитие методов и средств электрокардиографии происходит по пути формирования нового направления в ЭКГ диагностике - неинвазивной электрофизиологии $[1,3]$. Данное направление основано на современных методах регистрации, цифровой обработки и отображения электрокардиосигналов, которые позволяют измерять и оценивать дополнительные данные, недоступные стандартным методикам оценки ЭКГ. 